\title{
Identification of the Dopamine D3 Receptor in Oligodendrocyte Precursors: Potential Role in Regulating Differentiation and Myelin Formation
}

\author{
Ernesto R. Bongarzone, ${ }^{1}$ Sherrel G. Howard, ${ }^{1,2}$ Vilma Schonmann, ${ }^{1}$ and Anthony T. Campagnoni ${ }^{1}$ \\ ${ }^{1}$ Mental Retardation Research Center and Brain Research Institute and ${ }^{2}$ Molecular and Medical Pharmacology, School of \\ Medicine, University of California at Los Angeles, Los Angeles, California 90024
}

Expression of the dopamine D3 receptor (D3r) was found in primary mixed glial cultures from newborn brain and in the corpus callosum in vivo during the peak of myelination. Expression of the D3r mRNA, but not D2r mRNA, was detected as early as $5 \mathrm{~d}$ in vitro (DIV) by RT-PCR. Immunoblot studies revealed D3r protein was also expressed in the cultures. Double immunofluorescence analysis for the D3r and for surface markers of specific stages of oligodendrocyte development indicated that D3r expression occurred in precursors and in immature oligodendrocytes but not in mature oligodendrocytes (i.e., $\mathrm{A}_{2} \mathrm{~B} 5^{+} 007^{-} 01^{-}$and $\mathrm{A} 2 \mathrm{~B} 5{ }^{+} 007^{+} 01^{-}$cells but not A2B5 ${ }^{-}$ $007^{+} 01^{+}$cells). Confocal microscopic analysis indicated that D3r was associated with cell bodies and cell membranes but not with the processes emanating from cell somas. Immunohistochemistry of brain sections revealed the presence of D3r in some oligodendrocytes located mainly within the genu and

The D2 subfamily of dopamine receptors (D2r, D3r, and D4r) contains seven transmembrane regions (Bunzow et al., 1988; Sokoloff et al., 1990; Van Tol et al., 1991), a feature commonly associated with the members of the superfamily of G-proteincoupled receptors (Sibley et al., 1992). Although the activation of $\mathrm{D} 2 \mathrm{r}$ and D4r involves the inhibition of adenyl cyclase (Sibley et al., 1992), the second messenger system associated with D3r has remained elusive (Sokoloff et al., 1992). The D3r gene encodes a 446 amino acid protein with an overall homology of $52 \%$ with $\mathrm{D} 2 \mathrm{r}$, which increases to $75 \%$ in the transmembrane domains (Sokoloff et al., 1990). Recently, a shorter isoform of D3r (425 amino acids) has been described in the mouse, which appears to be pharmacologically active (Fishburn et al., 1993). The significance of these long and short active isoforms of D3r is still unknown, but their presence might be related to differential modulation of the dopaminergic system.

Like other neurotransmitter receptors, dopamine receptors are found within specific synaptic circuits in the CNS. The D3 receptor subtype is expressed earlier than other dopamine receptor subtypes. Fishburn et al. (1996) were able to demonstrate the presence of $\mathrm{D} 3$ receptor mRNA expression in mice as early as day

Received Jan. 27, 1998; revised April 16, 1998; accepted May 1, 1998

This work was supported by Grant NS23022 from the National Institutes of Health and Grants RG2693 (A.T.C.) and PP0573 (S.G.H.) from the National Multiple Sclerosis Society.

Correspondence should be addressed to Anthony T. Campagnoni, Mental Retardation Research Center and Brain Research Institute, School of Medicine, University of California at Los Angeles, 760 Westwood Plaza, Los Angeles, CA 90024. Copyright (C) 1998 Society for Neuroscience $0270-6474 / 98 / 185344-10 \$ 05.00 / 0$ radiato of the corpus callosum during the active period of myelination.

Treatment of cultures with $20 \mu \mathrm{m}$ quinpirole led to decreased numbers of $\mathrm{O}^{+}$oligodendrocytes possessing myelin-like membranes as well as an increase in the number of precursors in 14 DIV cultures. This effect was prevented by the dopamine antagonist haloperidol. These results show that the D3r expression is not restricted to neurons but it is also expressed in differentiating oligodendrocytes before terminal maturation. It also suggests that dopamine or some other D3r ligand may play a role in oligodendrocyte differentiation and/or the formation of myelin by mature oligodendrocytes.

Key words: myelination; dopamine receptors; brain development; cell lineage; oligodendroglia; neurotransmitters
9.5 postconception ( $\mathrm{pc}$ ), whereas the $\mathrm{D} 2$ receptor subtype was not detectable before day $13.5 \mathrm{pc}$. The distribution and expression of $\mathrm{D} 3 \mathrm{r}$ in the brains of many species have been reported, including mouse (Demotes-Mainard et al., 1996), rat (Levesque et al., 1992; Landwehrmeyer et al., 1993a; Larson and Ariano, 1995), and human (Landwehrmeyer et al., 1993b), and they vary greatly depending on the area in the brain (Richtland et al., 1995). As the brain matures, the regional distribution of D3r becomes more defined, overlapping little with the D2r, (Gehlert et al., 1992; Diaz et al., 1995). During postnatal development, D3r mRNA concentrates in the mesocorticolimbic complex, with the highest levels occurring in the nucleus accumbens, the Islands of Calleja, and the olfactory tubercle (Levesque et al., 1992; Landwehrmeyer et al., 1993a; Ariano and Sibley, 1994).

The finding that some neurotransmitter receptors are actively expressed before the development and establishment of cortical and subcortical synapses during early embryonic development has raised the possibility of alternative biological functions for these receptors, in addition to their well described participation in synaptic transmission (Mattson, 1988). We have recently reported the expression of the D2r in oligodendrocytes (Howard et al., 1998), suggesting a possible nonsynaptic function for dopamine in these myelin-forming cells.

The purpose of this study was to examine the expression of the D2 receptor subfamily in oligodendrocytes in vitro and in vivo. Primary glial cultures have been well characterized and have proven to be excellent models for examining the developmental expression of genes important for oligodendrocyte survival and differentiation (Temple and Raff, 1985; Gard and Pfeiffer, 1990; 
Cameron and Rakik, 1991; Barres et al., 1993). A large array of stage-specific markers is available with which to correlate gene expression and differentiation state. Mature oligodendrocytes within these cultures elaborate myelin-like membrane sheets providing a good in vitro model for examining one of the major functions of this cell type. In this communication, we describe the identification of D3r in immature oligodendrocytes in vitro and in oligodendrocytes in vivo during the period of major myelin deposition, and we provide evidence that D3r may modulate the timing of oligodendrocyte maturation and subsequent elaboration of myelin sheaths.

\section{MATERIALS AND METHODS}

Tissue collection and cell culture. Brain cortices and olfactory tubercle and Island of Calleja areas collected from postnatal day 7 (P7) mouse brains were immediately frozen at $-80^{\circ} \mathrm{C}$. The procedure for culture of glial cells has been described in detail elsewhere (Bongarzone et al., 1996). Briefly, newborn (0- to 3-d-old) mouse cerebral hemispheres were dissociated through a nylon mesh, and cells were collected in $50 \mathrm{ml}$ of $10 \%$ fetal calf serum DMEM. The cell suspension was poured through two collector tissue sieves (230 and $140 \mu \mathrm{m}$ pore size) and centrifuged for $5 \mathrm{~min}$ at $100 \times \mathrm{g}$. The cells, $15 \times 10^{6}$, were resuspended in $10 \mathrm{ml}$ of medium and plated on $75 \mathrm{~cm}^{2}$ culture flasks previously coated with poly-L-lysine and incubated at $37^{\circ} \mathrm{C} 5 \% \mathrm{CO}_{2}$, with changes of medium every $4 \mathrm{~d}$. Pellets of glial cells were prepared after 5, 7, 9, 11, 14, and $18 \mathrm{~d}$ in vitro (DIV) and immediately frozen in liquid nitrogen. Primary cultures were also grown on poly-L-lysine-coated glass coverslips and fixed at the time points mentioned by incubation with $4 \%$ paraformaldehyde in $1 \times$ PBS for $20 \mathrm{~min}$ at room temperature. Six-day-old primary cultures were treated with quinpirole, haloperidol, or the combination of both drugs, with changes of drug-containing medium every $2 \mathrm{~d}$. Cells were collected for RNA isolation after $8 \mathrm{~d}$ of treatment (14 DIV after cell plating). In some cases, glial cells were grown on glass coverslips and then were fixed and processed for immunocytochemistry as described below. In other experiments, treatment was canceled 6 DIV after initiation, and cells were maintained in drug-free medium for another 4 DIV before being fixed and processed for immunocytochemistry.

Extraction of RNA, cDNA synthesis, and RT-PCR reactions. Brain tissue or cell pellets were homogenized in an appropriate volume (100 $\mathrm{mg}$ of tissue/ml) of Trizol reagent (Life Technologies, Gaithersburg, MD) at $20,000 \mathrm{rpm}$ for $30 \mathrm{sec}$ (Polytron). Samples were incubated for $30 \mathrm{~min}$ at room temperature before extraction with chloroform for $5 \mathrm{~min}$. After centrifugation at $7000 \mathrm{rpm}$ at $4^{\circ} \mathrm{C}$, the aqueous phase was transferred to a new tube, and total RNA was precipitated with isopropanol at $-20^{\circ} \mathrm{C}$ for a minimum of $1 \mathrm{hr}$. RNA was washed in $75 \%$ ethanol, redissolved in DEPC-treated water at a final concentration of $5 \mathrm{mg} \mathrm{RNA} / \mathrm{ml}$, and stored at $-80^{\circ} \mathrm{C}$

First-strand cDNA was synthesized by priming $20 \mu \mathrm{g}$ of total RNA with an oligo-d $\mathrm{T}_{15}$ and extension with Superscript reverse transcriptase (Life Technologies) at $42^{\circ} \mathrm{C}$ for $60 \mathrm{~min}$. Two microliters of the first-strand cDNA preparation were used as template in PCR reactions with the following specific sense and antisense oligonucleotide primers: (1) D35, 5'-CCCTGTCCTACTGTGCACTCATC; and D33, 5'-ATAGAATCTTGAGGAAGGCTTTG; these primers direct the amplification from nucleotide 97 to 1333 for the mouse D3r cDNA (Fishburn et al., 1993); and (2) D25, 5'-GGCGCCCTATGGCTTGAAGAG; and D23, 5'CCTAGGCAGGGAGGCGGCAAG; these primers direct the amplification from nucleotide 78 to 1512 for the mouse D2r cDNA (Montmayeur et al., 1991). PCR conditions were 35 cycles, denaturation at $94^{\circ} \mathrm{C}$ for $1.5 \mathrm{~min}$, annealing at $63^{\circ} \mathrm{C}(\mathrm{D} 3 \mathrm{r})$ or $64^{\circ} \mathrm{C}(\mathrm{D} 2 \mathrm{r})$ for $1.5 \mathrm{~min}$, and extension at $72^{\circ} \mathrm{C} 1.5 \mathrm{~min}$. PCR products were analyzed in a $1.5 \%$ agarose gel.

Cloning and sequencing. PCR fragments were cloned into the pCR 2.1 sequencing vector (Invitrogen, San Diego, CA). Sequence analysis was performed on cloned DNA strands by the Sanger dideoxy chain termination method (Sambrook et al., 1989) with $\left[\alpha-{ }^{35}\right.$ S $]$ dATP (DuPont NEN, Boston, MA) using one unit of Sequenase version 2.0 (United States Biochemicals, Cleveland, $\mathrm{OH})$ per reaction.

Southern blot. Ten microliters of D3 RT-PCR-amplified products were separated by electrophoresis in a $1.5 \%$ agarose gel and transferred to a nylon membrane as described by Sambrook et al. (1989). After baking the membrane at $80^{\circ} \mathrm{C}$ for $2 \mathrm{hr}$, DNA was cross-linked by UV irradiation. The blot was prehybridized with hybridization solution [2× SSC (1 $\times \mathrm{SSC}=150 \mathrm{~mm} \mathrm{NaCl}$ and $15 \mathrm{~mm}$ sodium citrate, $\mathrm{pH} 7.2), 1 \times$ Den- hardt's solution, $0.1 \mathrm{mg} / \mathrm{ml}$ sheared salmon sperm DNA (SS-DNA), 100 $\mathrm{mm}$ Tris- $\mathrm{HCl}, \mathrm{pH} 7.6$, and $1 \%$ SDS] without the probe at $55^{\circ} \mathrm{C}$ for $2 \mathrm{hr}$. A specific oligonucleotide primer (5'-ATTTCAGCCGCATTTGCTGTG), whose sequence corresponds to nucleotides 289-310 from the D3r cDNA, was end-labeled with $\left[\gamma_{-}{ }^{32} \mathrm{P}\right] \mathrm{dATP}$ in the presence of T4 nucleotide kinase for $30 \mathrm{~min}$ at $37^{\circ} \mathrm{C}$. The probe was further purified from nonincorporated radioactivity by ethanol precipitation. Hybridization $\left(3 \times 10^{6} \mathrm{cpm} / \mathrm{ml}\right)$ was performed at $55^{\circ} \mathrm{C}$ for $18 \mathrm{hr}$. Blot was washed $\left(1 \times \mathrm{SSC}\right.$ and $1 \% \mathrm{SDS}$ at $\left.37^{\circ} \mathrm{C}\right)$ and exposed for $30 \mathrm{~min}$ at room temperature.

In situ hybridization. Sense and antisense oligonucleotide primers (same used for RT-PCR) specific for D3r sequence were end-labeled with digoxigenin (DIG)-UTP as recommended by the manufacturer (Boehringer Mannheim, Indianapolis, IN). Fixed cultures were treated for 10 min with PBS containing $0.3 \%$ Triton X-100. Samples were washed twice (5 min each) with PBS and then incubated for $10 \mathrm{~min}$ at $37^{\circ} \mathrm{C}$ with $100 \mathrm{~mm}$ Tris- $\mathrm{HCl}$ and $50 \mathrm{~mm}$ EDTA, $\mathrm{pH} 8.0$, containing $10 \mu \mathrm{g}$ of RNase-free proteinase $\mathrm{K} / \mathrm{ml}$. Samples were rinsed twice in $2 \mathrm{mg} / \mathrm{ml}$ glycine in PBS and post-fixed for $10 \mathrm{~min}$ in $0.1 \%$ glutaraldehyde and $2 \%$ paraformaldehyde in PBS. Samples were then prehybridized for $2 \mathrm{hr}$ at $42^{\circ} \mathrm{C}$ with hybridization buffer $(50 \%$ deionized formamide, $1 \times$ Denhardt's solution, $4 \times$ SSC, $1 \%$ SDS, $0.1 \mathrm{mg} / \mathrm{ml}$ yeast tRNA, and $0.1 \mathrm{mg} / \mathrm{ml}$ SS-DNA) before hybridization for $18 \mathrm{hr}$ at $42^{\circ} \mathrm{C}$ in this solution containing $100 \mathrm{ng} / \mathrm{ml}$ DIG-labeled primer. Samples were washed at $40^{\circ} \mathrm{C}$ in $50 \%$ formamide and $1 \times$ SSC and at room temperature in $1 \times$ SSC and then blocked with 5\% normal goat serum in Tris-buffered saline (TBS). Bound DIG probe was detected with anti-DIG antibodies (1:500). Preparations were washed in TBS and then incubated with nitroblue tetrazolium and X-phosphate as recommended by the manufacturer (Boehringer Mannheim). Color reaction was developed overnight in the darkness and stopped by rinsing the samples in $10 \mathrm{~mm}$ Tris- $\mathrm{HCl}, 1 \mathrm{~mm}$ EDTA, and distilled water. Slides were mounted in Aquamount (Pittsburgh, PA).

Immunoblot. Membrane associated proteins were extracted with $0.1 \%$ Triton X-100 in the presence of a mixture of protease inhibitors, and 100 $\mu \mathrm{g}$ was electrophoresed in a $12 \%$ acrylamide-SDS gel (Laemmli, 1970). Proteins were electrotransferred onto nitrocellulose membranes (Towbin et al., 1979), and blots were incubated with 5\% nonfat milk (Carnation) in TBS for $1 \mathrm{hr}$ at room temperature. Polyclonal antibodies that recognize the $\mathrm{C}$ terminus of the $\mathrm{D} 3 \mathrm{r}$ were diluted 1:1000 in $0.5 \%$ blocking solution and incubated with the blots for $3 \mathrm{hr}$ at room temperature. After washing the membranes with fresh $0.01 \%$ Tween 20 in TBS, goat antirabbit IgG antibodies labeled with horseradish peroxidase were diluted 1:1500 and incubated with the blots for $1 \mathrm{hr}$ at room temperature. Immunocomplexes were visualized by enhanced chemiluminescence (Pierce, Rockford, IL).

Immunocytochemistry. Fixed cells were permeabilized by incubation with $0.01 \%$ Triton X-100 in PBS for $1.5 \mathrm{~min}$ at room temperature. Coverslips were blocked with 5\% normal sheep serum (NSS) in PBS at room temperature for $2 \mathrm{hr}$. Samples were then incubated with the following primary specific antibodies diluted in $0.5 \%$ NSS and $0.01 \%$ Tween 20 in PBS: goat polyclonal D3r anti-C terminus, 1:800 (Santa Cruz Biotechnology, Santa Cruz, CA); mouse monoclonal anti-A2B5, 1:50 (American Type Culture Collection, Manassas, VA); mouse monoclonal anti-galactocerebroside (O1), 1:100 (Dr. A. Gard, Department of Structural Biology, University of South Alabama); mouse monoclonal antiOO7, 1:100; monoclonal mouse anti-neurofilament, $68 \mathrm{kDa}, 1: 100$ (Chemicon, Temecula, CA); and rabbit polyclonal anti-neuron-specific enolase, 1:2000 (Chemicon). The first incubation was performed at $4^{\circ} \mathrm{C}$ for $18 \mathrm{hr}$. Samples were rinsed thoroughly with PBS and incubated with a 1:800 dilution of the appropriate secondary antibodies labeled with fluorescein or rhodamine (Boehringer Mannheim) for $2 \mathrm{hr}$ at room temperature. Samples were then rinsed in PBS and then mounted on glass slides with Aquamount. Preparations were observed by epifluorescence with a Leica DMR microscope and by confocal microscopy using a Zeiss LSM confocal microscope.

Immunohistochemistry. BALB/c mice at P3, P9, P14, and $\mathrm{P} 25$ and adult animals were profoundly anesthetized using halothane, perfused using a chilled sterile solution of PBS, and then fixed with $2 \%$ paraformaldehyde in PBS. Brains were dissected out and post-fixed overnight in $4 \%$ paraformaldehyde in PBS. Tissue was cryoprotected with OCT, frozen, and then used to cut coronally oriented sections. Sections were processed for immunohistochemistry using the free-floating technique. Endogenous peroxidase activity was quenched by incubating the sections in $0.1 \%$ $\mathrm{H}_{2} \mathrm{O}_{2}$ in PBS for 15 min. Tissue was then blocked in $10 \%$ normal rabbit 
A

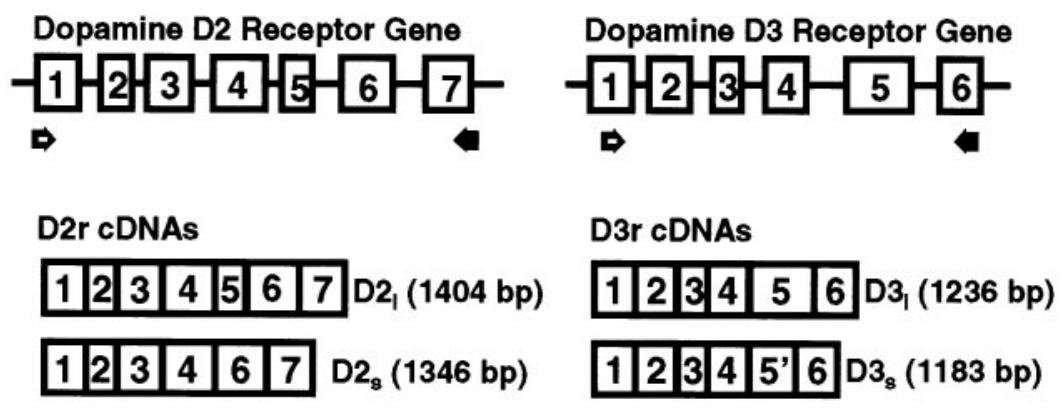

Figure 1. Primary cultures of glia express the D3r but not the D2r mRNA. The message for both dopamine receptors was detected by RT-PCR analysis. $A$, The scheme illustrates the structural organization of the D2r and D3r genes and their mRNAs. Two sets of specific oligonucleotide primers (open arrows, sense primers; filled arrows, antisense primers) were designed to amplify the cDNAs containing the open reading frame sequence for these receptors. $B$, Ethidium bromide staining of RT-PCR fragments. The $\mathrm{mR}$ NAs for both isoforms of the D2r were detected in a P7 brain sample, although no expression of this receptor was evidenced by RT-PCR in the glial samples at 7 or 14 DIV. The 1236 bp cDNA for the long D3r was readily amplified from the P7 brain sample. A single band with the same relative size was also detected in RNA samples from 7 and 14 DIV primary cultures of glia.

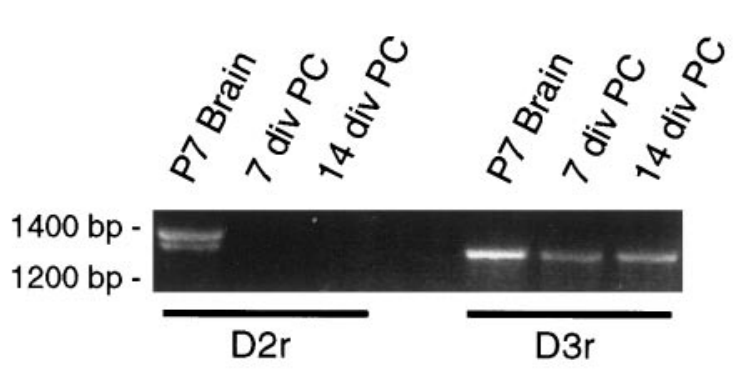

B

serum (NRS) in PBS for $2 \mathrm{hr}$ at room temperature. Sections were incubated with goat anti-D3r antiserum (Santa Cruz), diluted 1:600 in $1 \% \mathrm{NRS}$ and $0.02 \%$ Tween- 20 for $72 \mathrm{hr}$ at $4^{\circ} \mathrm{C}$. Bound primary antibody was detected using the avidin-biotin-peroxidase system as recommended by the manufacturer (Vector Laboratories, Burlingame, CA). After development with diaminobenzidine, nickel ions, and $\mathrm{H}_{2} \mathrm{O}_{2}$, sections were mounted on gold-plus slides (Fisher Scientific), air-dried, dehydrated with serial graded ethanol, clarified in xylenes, and coverslipped with Permount.

\section{RESULTS}

Glial cells express the D3r in 14 DIV primary cultures

We analyzed whether cultured oligodendrocytes might express the principal members of the D2 subfamily of dopamine receptors during their in vitro differentiation. Glial cell cultures were established from newborn mice (P0-P3) and maintained for 2-3 weeks. Under the experimental conditions described in this study, any contaminating neurons, a potential source of dopamine receptors, did not survive. This was confirmed by the absence of immunoreactivity to the neuronal $68 \mathrm{kDa}$ neurofilament and neuron-specific enolase (data not shown).

Glial cells were harvested at 7, 14, and 18 DIV, and their mRNAs were reverse-transcribed and used in PCR experiments designed to specifically detect the presence of either the D3r or the D2r mRNA. Primers D35 and D33 were chosen for the amplification of the long (1236 bp) and the short (1183 bp) isoforms of D3r (Fig. 1A), and primers D25 and D23 were selected to amplify the long (1404 bp) and the short (1346 bp) isoforms of the D2r (Fig. 1A). Both isoforms of the D2r were easily detected in the P7 mouse brain sample (Fig. 1B). In contrast, neither D2r isoform was detected in 7 or 14 DIV primary glial cultures (Fig. $1 B$ ) or in 18 DIV preparations (data not shown). The long isoform of the D3r, but not the short isoform, was amplified from P7 mouse brain (Fig. 1B). Interestingly, an intense band corresponding to the long D3r mRNA was detected in both 7 and 14 DIV primary cultures of mouse glia
(Fig. $1 B$ ). The same result was obtained with a sample from 18 DIV primary cultures.

To confirm the identity of the putative long D3r detected in the glial cultures, PCR fragments were subcloned and sequenced, and the products were found to be $100 \%$ homologous with the mouse long D3r (Fishburn et al., 1993).

\section{Process-bearing cells express the D3r mRNA}

Our primary cultures of glia are composed of a mixture of astrocytes $(\sim 70 \%)$, oligodendrocytes $(\sim 20 \%)$ and microglia $(\sim 10 \%)$. Thus, the mRNA encoding the long D3r might have arisen from any of these cell types. To determine the cellular origin of the D3r expression, an in situ hybridization analysis was performed with specific D3r sense and antisense oligonucleotides labeled with digoxigenin. Figure 2 shows the results of such an experiment performed with a D3r antisense (Fig. 2B) and a control sense probe (Fig. $2 A$ ). With the antisense probe a strong, specific signal could be detected primarily within process-bearing cells of the size and morphology of cells in the oligodendroglial lineage. No labeling of astrocytes was evident.

\section{Developmental expression of the D3r begins around 5} DIV in primary cultures of glia

We analyzed changes in the expression of the D3r mRNA with time in culture. The D3r mRNA was reverse transcribed and amplified by PCR at different stages over a period of 2 weeks after plating. The PCR fragments were identified by Southern blot using a D3r-specific radiolabeled oligonucleotide. A single band with the predicted size of $\sim 1.2 \mathrm{~kb}$, corresponding to the long isoform of the D3r, was detected in the control RNA sample isolated from P7 mouse brain (Fig. $3 A$ ). A similar band was also identified in all the RNA samples isolated from primary glial cultures, ranging from 5 to 14 DIV (Fig. $3 A$ ). Although not a quantitative analysis, the experimental conditions for the RTPCR were strictly maintained for all the samples, and there were 

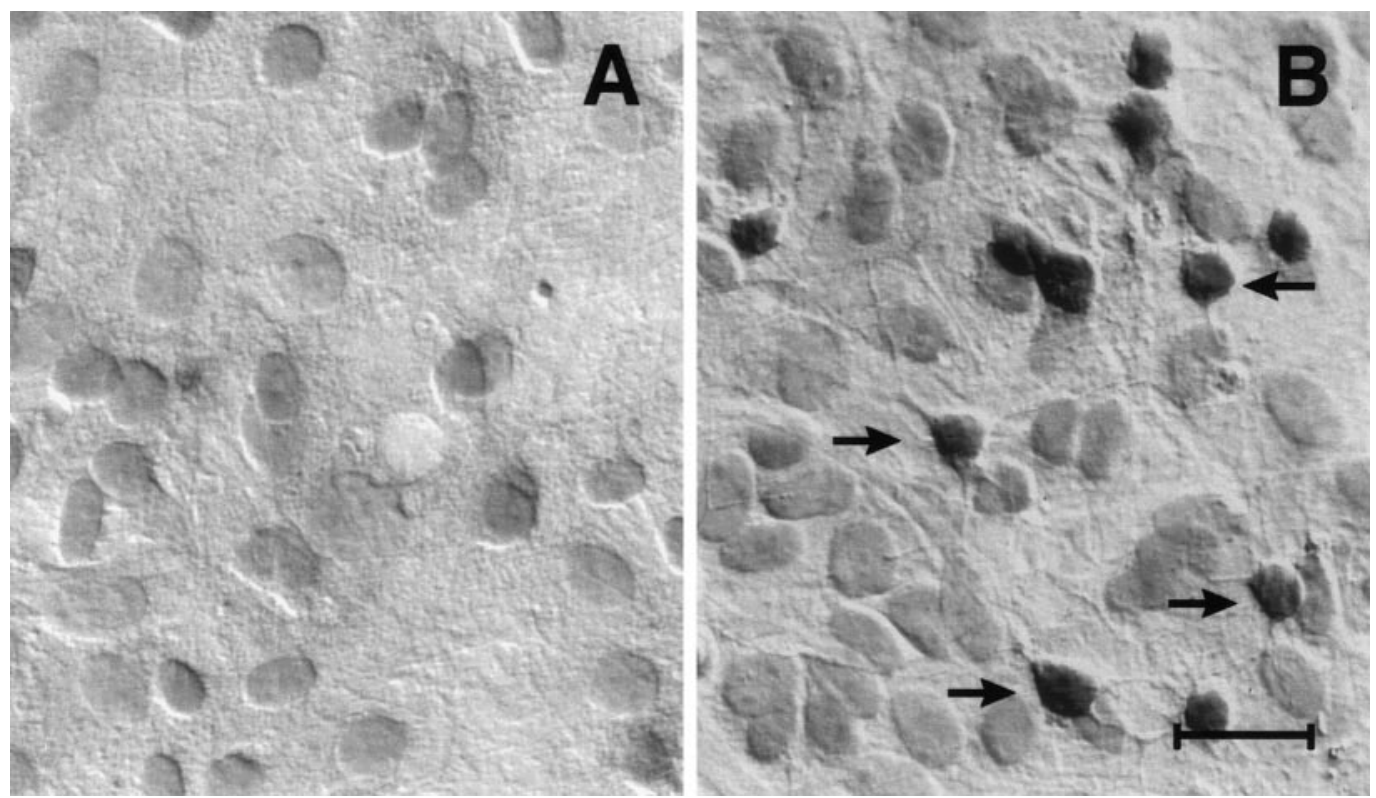

Figure 2. D3r mRNA is produced in oligodendroglial-like cells in culture. D3r message was detected in 14 DIV primary cultures of mouse glia by in situ hybridization using an antisense oligonucleotide labeled with digoxigenin specific for the $3^{\prime}$ end of exon 6 of D3r $(B)$. Note that only cells with the morphology described for oligodendrocytes were detected. The staining is restricted to only the oligodendroglial cell bodies, and no message was evidenced within the cellular processes. The astrocytic layer (lining underneath the oligodendrocytes) was barely stained, and it is comparable to the nonspecific staining using a sense oligonucleotide $(A)$. Scale bar, $20 \mu \mathrm{m}$.

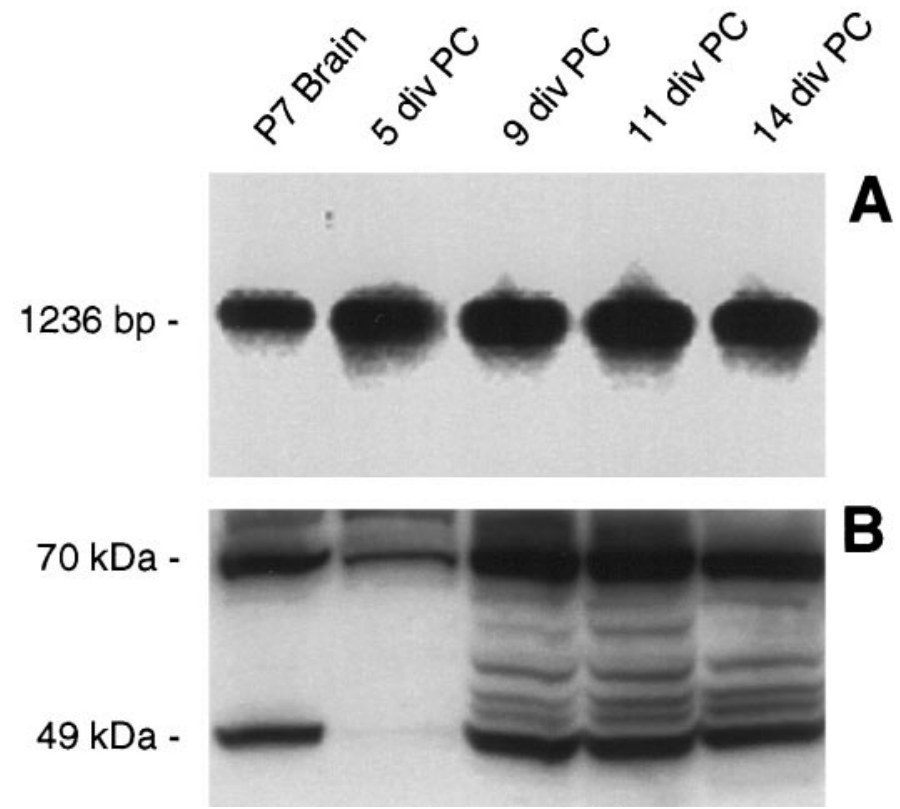

Figure 3. The in vitro expression of D3r seems to follow a developmentally regulated pattern. $A$, By Southern blot analysis using a specific radiolabeled internal oligonucleotide, D3r message was identified in RTPCR samples generated from P7 brain and glial primary cultures at 5, 9, 11 , and 14 DIV. $B$, By immunoblot detection, D3r proteins were detected in the membrane extracts from the olfactory tubercle isolated from P7 brain as a $49 \mathrm{kDa}$ product (possibly the nonglycosylated form of the receptor) and a $70 \mathrm{kDa}$ product (possibly the glycosylated form of the receptor). D3r proteins were also immunodetected in membrane proteins extracted from primary cultures at 5, 9, 11, and 14 DIV.

no evident changes in the intensity of the bands, suggesting that the expression of the D3r mRNA is maintained at similar levels over the first 2 weeks of culture.

We investigated whether the D3r mRNA was translated into protein by Western blot analysis. Using an antibody specific to the $\mathrm{C}$ terminus of the $\mathrm{D} 3 \mathrm{r}$ protein, we were able to detect the immature, presumably nonglycosylated, state of the D3r with the predicted relative molecular weight of $49 \mathrm{kDa}$ in a control membrane extract from the olfactory tubercle area of P7 mouse brain (Fig. $3 B)$. A high molecular weight band ( $\sim 70 \mathrm{kDa})$, presumably the fully glycosylated version of the receptor, was also immunodetected by the antibodies. The same basic pattern of the 49 and $70 \mathrm{kDa}$ proteins was identified in membrane protein extracts isolated from primary cultures (Fig. 3B). Interestingly, the level of D3r protein produced in glial cultures seemed to increase as the cultures aged, appearing to reach a peak of expression between 9 and $11 \mathrm{DIV}$ and then decreasing slightly at 14 DIV (Fig. $3 B$ ). The bands on the Western blots between 49 and $70 \mathrm{kDa}$ presumably represent D3r products with varying levels of glycosylation.

\section{$D 3 r$ is expressed primarily in immature oligodendrocytes and is localized in the plasma membrane and cell bodies but not in the cell processes}

Oligodendrocyte differentiation in vitro has been examined extensively with the use of stage-specific markers. Through the use of double immunocytochemistry, we were able to study the coexpression of D3r with early and late markers of oligodendrocyte differentiation. At 7 DIV, oligodendrocyte precursors could be identified with markers such as A2B5 and GD3. At 7 DIV, oligodendrocyte precursors were stained with the monoclonal antibody A2B5 (Fig. 4B, red fluorescence). All the A2B5 ${ }^{+}$oligodendrocyte precursor cells were found to express D3r (Fig. 4B, arrows, green fluorescence). In these cells, the D3r immunoreactivity was found associated with cell bodies, and little immunoreactivity was detected in processes. At later stages (14 DIV) some oligodendrocytes that had reached the stage of myelin membrane formation were easily observed by staining with the mature oligodendrocyte marker O1. As seen in Figure $4 D$ these $\mathrm{O} 1^{+}$cells 

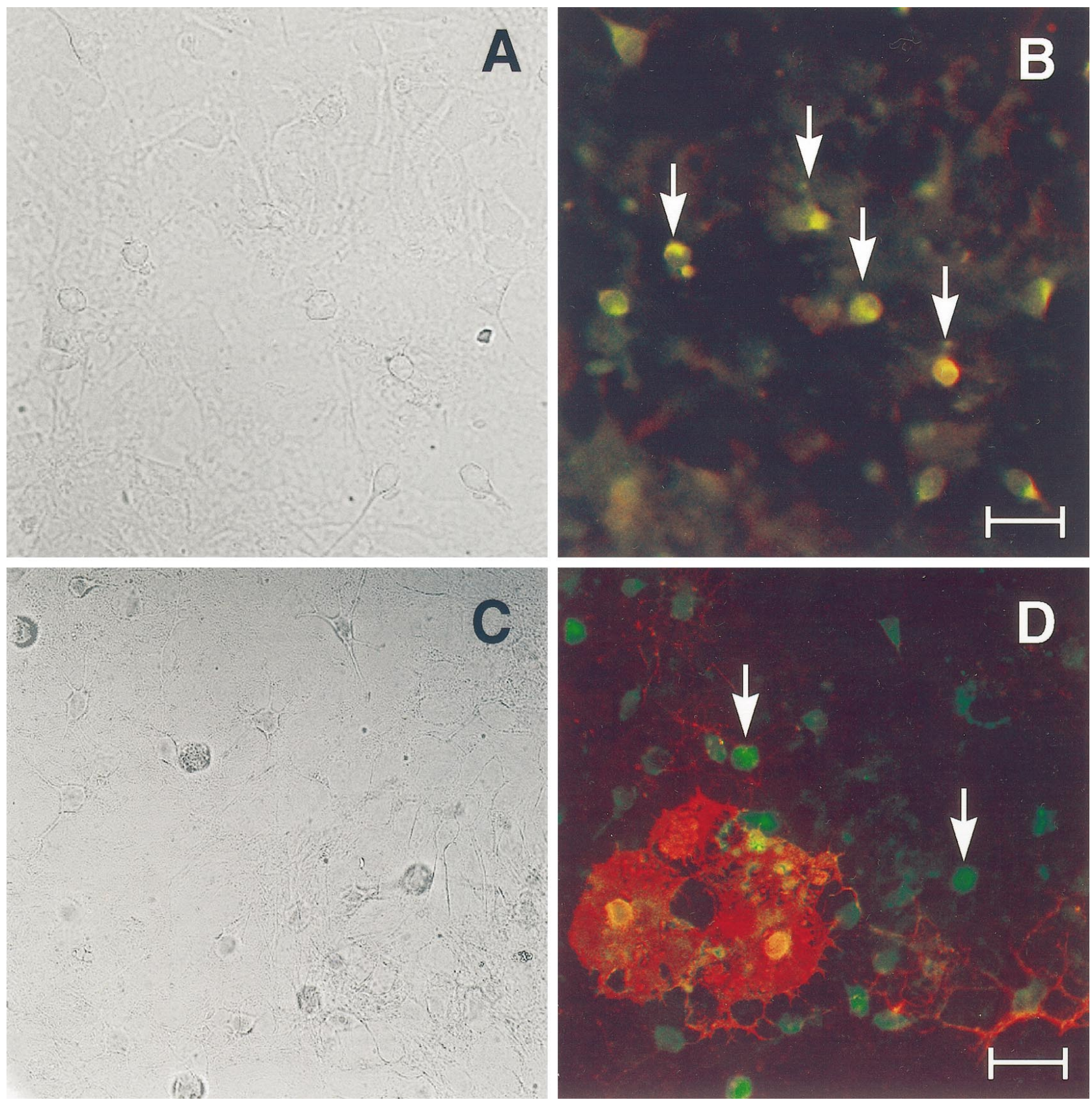

Figure 4. D3r colocalizes with A2B5 ${ }^{+}$but only occasionally with $\mathrm{O}^{+}$cells. Primary cultures were fixed at 7 DIV $(A, B)$ and 14 DIV $(C, D)$ and were analyzed by double immunofluorescence to detect D3r ( green) with A2B5 $(B)$ and $\mathrm{O} 1(D)(r e d)$. $A$, $C$, Phase-contrast micrographs corresponding to $B$ and $D$, respectively. D3r colocalized with the early oligodendroglial marker A2B5 in all progenitor cells $(B$, arrows). At later stages in differentiation, oligodendrocytes that have started the synthesis of myelin membranes (evidenced with the monoclonal antibody O1;D) were faintly stained in their soma with the antibody against $\mathrm{D} 3 \mathrm{r}(D)$. However, many $\mathrm{D} 3 \mathrm{r}^{+} \mathrm{O}^{-}$cells without visible processes were also observed $(D$, arrows). Scale bars: $B, 15 \mu \mathrm{m} ; D$, $20 \mu \mathrm{m}$.

(red fluorescence) elaborated flattened, myelin-like sheets. The somas of these $\mathrm{O} 1^{+}$cells stained only very weakly, if at all, with the anti-D3r antibody (Fig. 4D, green fluorescence). At this stage there were many $\mathrm{O} 1^{-} \mathrm{D} 3 \mathrm{r}^{+}$cells with the morphological characteristics of immature oligodendrocytes (Fig. 4D, arrows).

In these immunocytochemical studies, D3r was consistently observed to be associated with the cell bodies of the oligodendrocyte precursors, and very little signal was observed within their processes. To illustrate this differential localization more clearly, Figure 5 shows the subcellular distribution of D3r (red fluorescence) in 9 DIV primary cultures of glia doubly stained with 007 antibodies (green fluorescence) analyzed by confocal microscopy. The 007 is a surface marker that stains cells that are more differentiated than oligodendrocyte precursors, including immature and mature oligodendrocytes. As Figure 5 shows, D3r was observed in association with the cell bodies and cell membrane of the $007^{+}$cells but the processes of these cells (stained in green with 007) did not stain for D3r protein. Taken together, the double immunocytochemical studies indicate that D3r is expressed primarily in oligodendrocyte precursors and immature oligodendrocytes but not in mature oligodendrocytes. Furthermore, D3r does not appear to localize in the cell processes of these cells. 


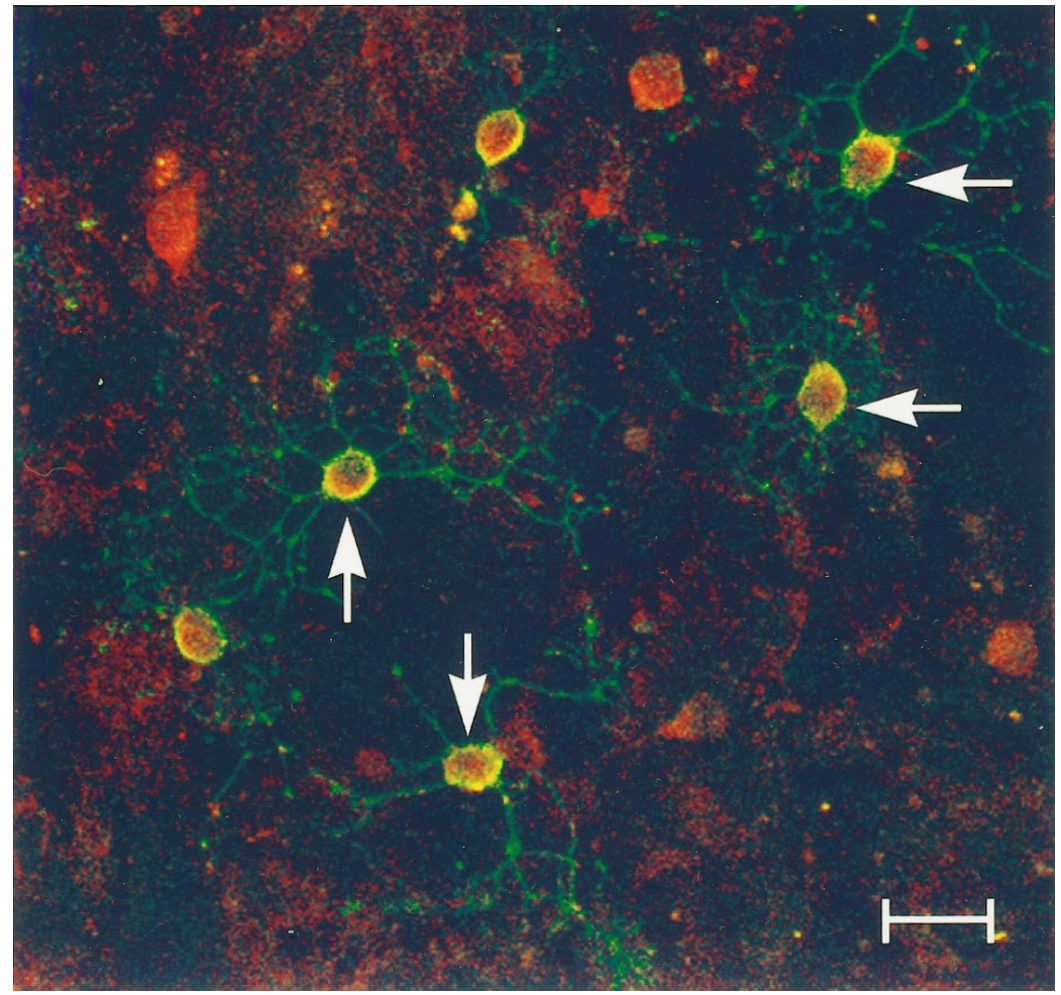

Figure 5. D3r was detected in association with the plasma membrane but not with the cellular processes in differentiating oligodendrocytes. The subcellular localization of the D3r was studied in double immunofluorescence (D3r, red; OO7, green) staining of 9 DIV primary cultures by confocal microscopy. D3r was detected in association with the plasma membrane of oligodendrocytes, which could be clearly evidenced with the OO7 antibody. D3r immunoreaction was also observed within the cytoplasm of these cells. A network of cellular processes was easily visualized with 007 ; however, no $\mathrm{D} 3 \mathrm{r}$ immunoreaction was detected in association with them. Scale bar, $20 \mu \mathrm{m}$.

\section{D3r is transiently expressed in oligodendrocytes located within the corpus callosum during the period of myelination}

We wanted to determine whether oligodendrocytes in vivo expressed the D3r. To do this we performed immunohistochemical studies with a D3r-specific antibody during the early postnatal period of brain development, just before maximal myelination in the brain. A number of brain structures showed immunodetectable levels of the receptor. During the developmental period examined, D3r expression was noted in large neurons located in the mesocorticolimbic area. Highest expression was observed in the Island of Calleja and olfactory tubercle. These areas showed the earliest expression of D3r (P3) that was maintained throughout the developmental period examined. Figure $6 B$ shows a representative field of a coronal section at the level of Island of Calleja of a P14 mouse brain in which D3r was localized in large clustered neurons of $\sim 20 \mu \mathrm{m}$ in diameter. D3r was also found expressed in pyramidal cells within layers 3 and 5 of the prefrontal cortex and in a lower level in the nucleus accumbens (data not shown).

To determine whether cells in the oligodendrocyte lineage expressed D3r, we focused our analysis on white matter areas, particularly in the corpus callosum in which $>90 \%$ of the cells are oligodendrocytes. Cells with small cell bodies stained with the anti-D3r antibody in fiber tracts located adjacent to the neocortex. These cells had small somal diameters $(\sim 7 \mu \mathrm{m})$ with the "string of pearls" orientation characteristic of interfascicular oligodendrocytes (Peters et al., 1991). In addition to these, cells of similar morphology and size were scattered individually throughout the white matter tracts (Fig. 6). At P3 very little immunostaining could be observed in these cells (Fig. 6C). However, at later stages of neural development (beginning at P9; data not shown), D3r was evident within these oligodendroglial cells, with a peak of expression observed at P14, approximately 1 week before maxi- mal myelination in this area (Fig. $6 D$ ). In the adult brain, white matter was barely immunoreactive, showing very few $\mathrm{D} 3 \mathrm{r}^{+}$cells in a scattered distribution throughout the fiber tracts (data not shown). These cells were of the size and morphology of small neurons. During development, $\mathrm{D} 3 \mathrm{r}^{+}$oligodendroglia was located almost exclusively in the genu of the corpus callosum, and some $\mathrm{D} 3 \mathrm{r}^{+}$cells were observed entering the radiato of the corpus callosum. No staining was evident in the external capsule or the anterior commissure. It is important to note that in all the cells analyzed, D3r was always associated with the cell bodies, and there was no immunostaining of the processes. Satellite and perivascular oligodendrocytes and astroglia did not show expression of the receptor at any stage of development.

\section{Treatment of glial cultures with the dopamine agonist quinpirole altered the normal pattern of oligodendrocyte differentiation}

It was of interest to determine whether the presence of the D3r had any functional significance for the oligodendrocyte. Accordingly, we examined whether quinpirole, a dopamine $\mathrm{D} 2 \mathrm{r} / \mathrm{D} 3 \mathrm{r}$ agonist, had any effect on oligodendrocyte differentiation and/or myelin formation in the glial cultures. In vitro differentiation of quinpirole-treated primary cultures was evaluated by counting the number of $\mathrm{A} 2 \mathrm{~B} 5{ }^{+}$cells, $\mathrm{O} 1^{+}$cells, and $\mathrm{O} 1^{+}$cells bearing myelin-like sheets in 14 DIV primary cultures. A2B5 was used as a marker for oligodendrocyte precursor cells, and $\mathrm{O} 1$ was used as a marker for mature oligodendrocytes. As shown in Figure $7 A$, there is normally a drop in the number of $\mathrm{A} 2 \mathrm{~B}^{+}$cells as the cultures mature. In this case the number of $\mathrm{A} 2 \mathrm{~B} 5{ }^{+}$cells decreased from 21 cells per field at 7 DIV to 9 cells per field at 14 DIV. Treatment of the primary cultures with the agonist quinpirole resulted in an increase in the number of $\mathrm{A} 2 \mathrm{~B} 5^{+}$cells in the 14 DIV cultures from 9 to 14 cells per field. To be certain that the effect of quinpirole was mediated through $\mathrm{D} 3 \mathrm{r}$, parallel primary 

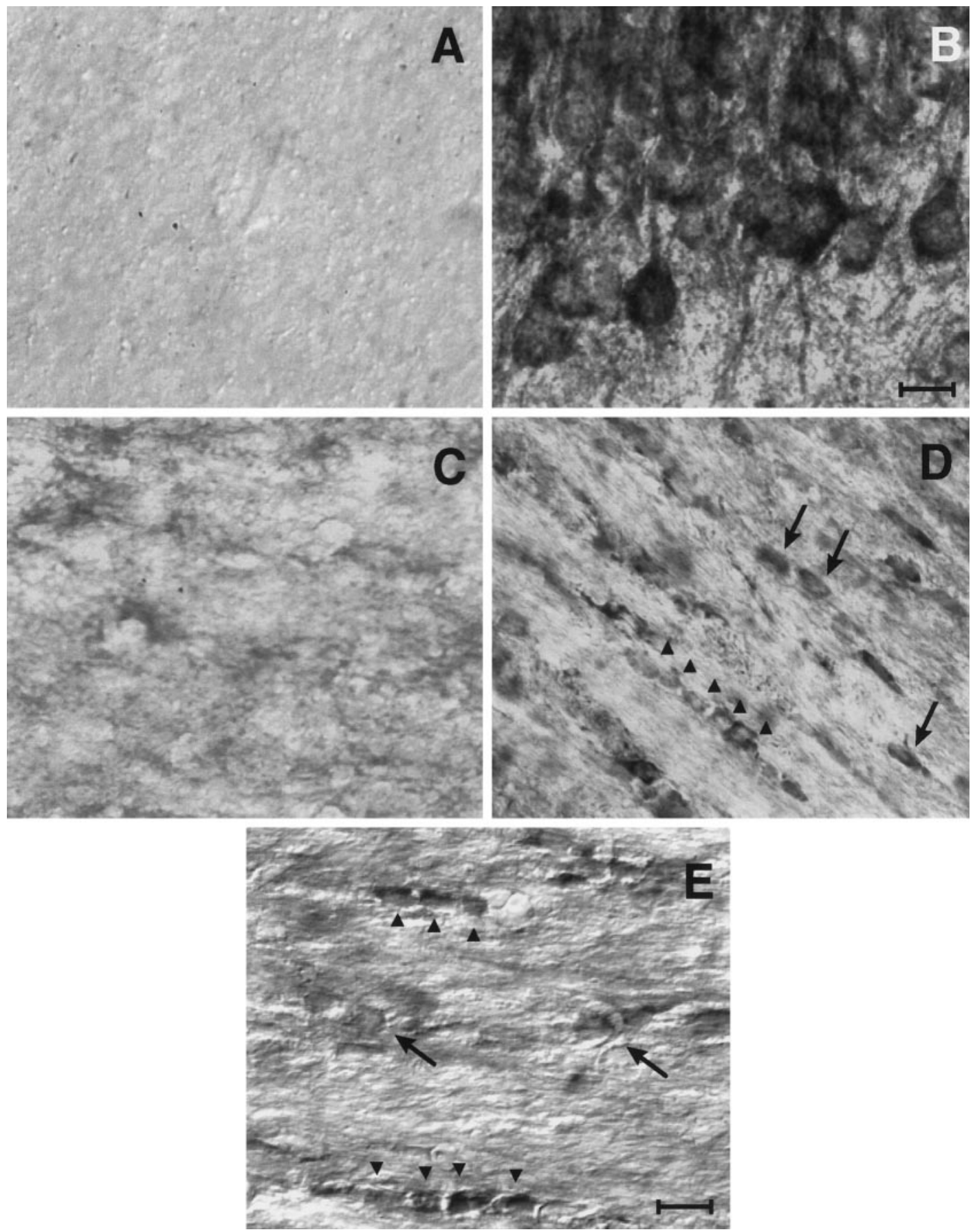

Figure 6. D3r was detected in differentiating oligodendrocytes in the corpus callosum. The anatomical distribution of D3r was examined by immunohistochemistry in brain sections during the first 4 postnatal weeks and in the adult brain. $A$, Nonspecific staining of P14 corpus callosum using nonimmune serum. $B$, Mesocorticolimbic large-sized neurons from Islands of Calleja were heavily immunostained with the anti-D3r antibody. $C-E$, Micrographs showing a portion of the genu corpus callosum immunostained with the anti-D3r antibody at P3 $(C), \mathrm{P} 14(D)$, and P25 $(E)$. Cells with small somal diameters $(\sim 7 \mu \mathrm{m})$ arranged in "strings" (arrowheads) or scattered individually throughout the white matter (arrows) were evident at P14 and to a lesser extent at P25. Scale bars: $B, 20 \mathrm{~mm} ; C-E, 10 \mathrm{~mm}$.

cultures were treated with quinpirole and the dopamine antagonist haloperidol. Under these conditions, the antagonist blocked the effect of the agonist, with the number of $\mathrm{A} 2 \mathrm{~B} 5^{+}$cells reaching levels similar to the untreated control at 14 DIV (Fig. 7A). Treatment with quinpirole had little effect on the number of oligodendrocytes at 14 DIV (Fig. $7 A$ ).

Interestingly, agonist stimulation of D3r led to a $46 \%$ decrease in the number of $\mathrm{O}^{+}$oligodendrocytes bearing myelin sheets compared with untreated controls (Fig. 7B). Furthermore, the presence of haloperidol antagonized the effect of quinpirole, increasing the number of oligodendrocytes bearing sheets to $92 \%$ of the untreated control. To investigate whether the effect of D3r on the formation of myelin membranes was irreversible, primary cultures were treated for 6 DIV and then switched to a drug-free medium for another 4 DIV before $\mathrm{O} 1^{+}$cells bearing myelin-like membranes were counted. Interestingly, the number of 


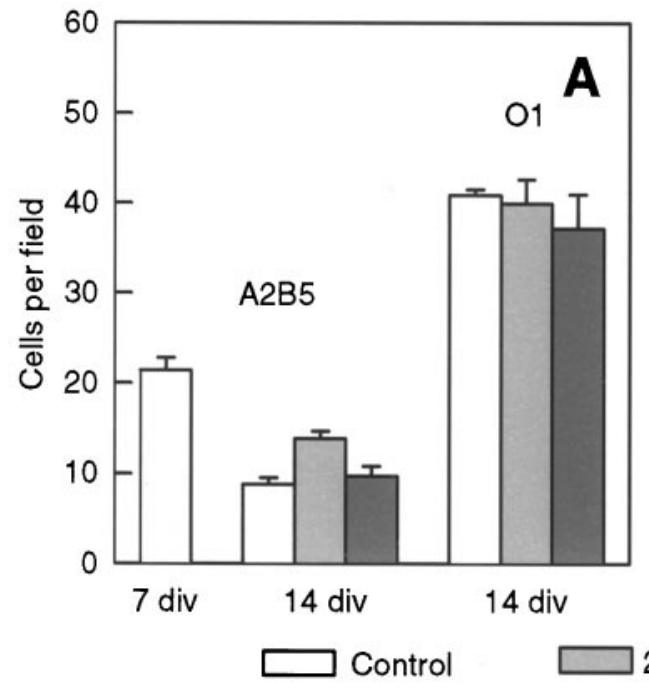

$20 \mu \mathrm{M}$ Quinpirole
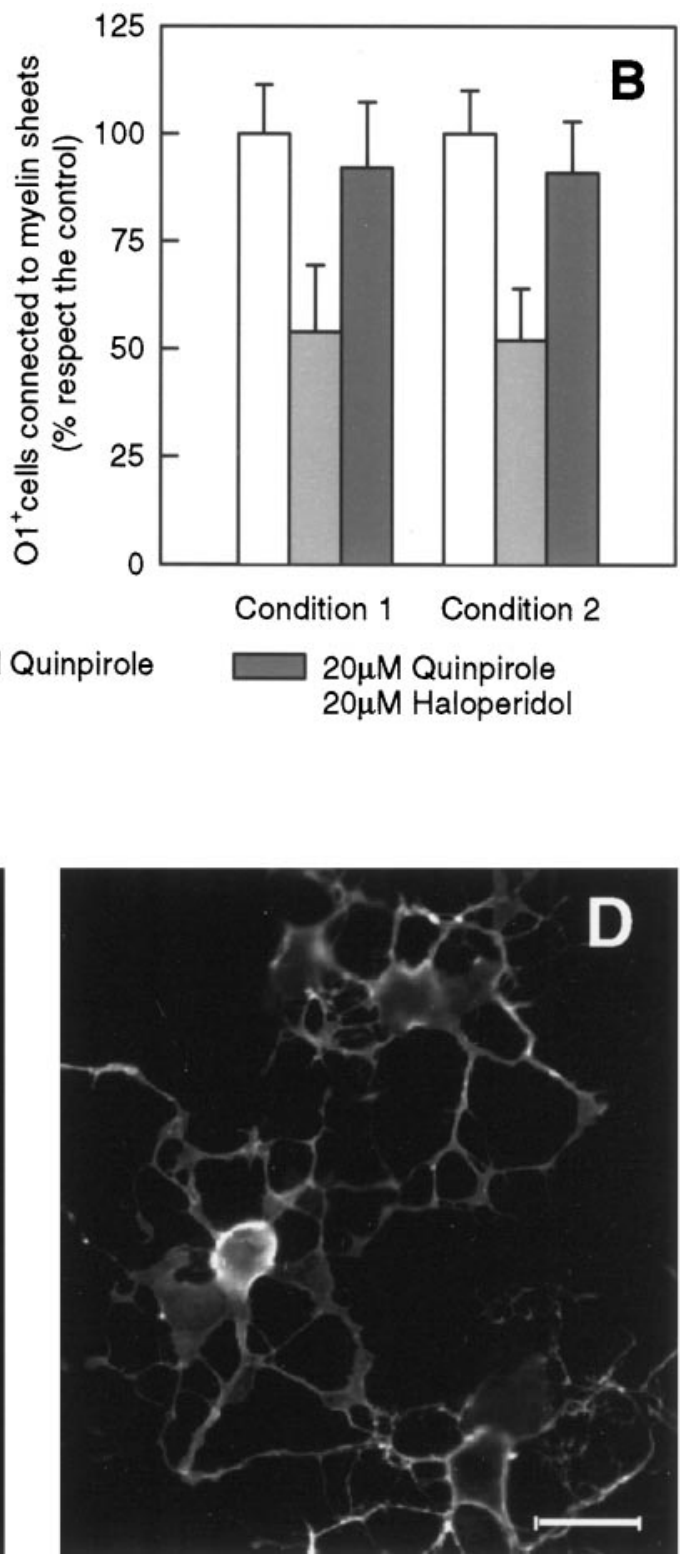

Figure 7. Stimulation of D3r by quinpirole decreased the in vitro differentiation of oligodendrocytes. $A$, The in vitro differentiation of oligodendrocytes was analyzed by counting the number of immature A2B5 ${ }^{+}$cells remaining in 14 DIV cultures and compared with the respective number in cultures at $7 \mathrm{DIV}$. The activation of D3r by quinpirole induced an increase of the number of A2B5 ${ }^{+}$cells in 14 DIV primary cultures with respect to the untreated control. This effect was blocked by coincubation with the antagonist haloperidol. Data are presented as the number of A2B5 ${ }^{+}$cells counted per field $(0.1$ $\left.\mathrm{mm}^{2}\right)$. At least 10 fields were observed from three separated experiments. Results were analyzed by the one-way ANOVA test $(p<0.05)$. The number of oligodendrocytes present at 14 DIV (analyzed by the presence of the marker O1) was also counted and analyzed as described previously. B, In vitro differentiation of oligodendrocytes was also evaluated by counting the number of $\mathrm{O}^{+}$cells connected to myelin-like membranes in $14 \mathrm{DIV}$ (condition 1) and 16 DIV (condition 2) primary cultures. In condition 1, quinpirole or haloperidol treatments were begun at 6 DIV and continued until 14 DIV, and cultures were analyzed. Under this condition quinpirole induced a marked decrease $(46 \%)$ of $\mathrm{O} 1^{+}$cells bearing myelin sheets compared with the untreated or haloperidol controls. In condition 2, quinpirole or haloperidol treatments were begun at 6 DIV, the drugs were removed at 12 DIV, and the cultures were analyzed at 16 DIV. Quinpirole treatment for day 6 appeared to be sufficient to reduce the numbers of sheet-bearing cells at 16 DIV with no apparent recovery after removal of the drug. Data represent the average of three separated experiments in triplicate and were analyzed by the one-way ANOVA test $(p<0.05)$. $C, D$, Immunofluorescence analysis of $\mathrm{O} 1^{+}$cells associated to myelin-like membranes in $14 \mathrm{DIV}$ control $(C)$ and quinpirole-treated $(D)$ primary cultures. Observe the lesser extension of myelin-like membranes in the treated samples $(D)$. Scale bar, $25 \mu \mathrm{m}$.

quinpirole-treated oligodendrocytes associated with myelin sheets $(51 \%)$ did not return to normal levels 4 DIV after withdrawal of the drug (Fig. $7 B$ ). However, the antagonizing effect of haloperidol increased the number of cells associated with myelin sheets to $92 \%$ of the untreated control (Fig. $7 B$ ). The dose of drugs used in these studies $(20 \mu \mathrm{M})$ did not produce any degeneration of the cultures and was substantially lower than that needed to cause a lethal effect on glial cells (data not shown). Figure 7, $C$ and $D$, illustrates the differences in membrane sheet formation between oligodendrocytes in the quinpirole-treated cultures (Fig. 7D) and untreated cultures (Fig. 7C). Larger numbers of oligodendrocytes in the control cultures elaborated more extensive areas of myelin sheets at 14 DIV than in the quinpiroletreated cultures. 


\section{DISCUSSION}

Our results show the expression of the D3r in immature oligodendrocytes in mouse primary glial cultures. We saw little or no expression of the D3r in mature oligodendrocytes. Interestingly, we were able to detect the D3r mRNA easily at 5 DIV, a time when immunoreactive protein on Western blots was detected at very low levels. Expression of the D3r in cells in the oligodendrocyte lineage was confirmed in vivo, particularly in cells within the corpus callosum before the period of maximal myelination in the mouse brain.

Our finding that the D3r is expressed in immature oligodendrocytes represents the third neurotransmitter receptor system to be identified in oligodendrocytes and their precursors. Gallo et al. (1989, 1996) have described the properties of the glutamate receptors in oligodendrocytes, and expression of the $\mathrm{GABA}_{\mathrm{A}}$ receptor has been reported in oligodendrocytes (Kettenmann, 1989; Von Blankenfeld et al., 1991). These results indicate that these neurotransmitter receptors are involved in processes other than nerve conduction in oligodendrocytes, and they raise the interesting question of what their functions might be in these glial cells. The concept that classical neurotransmitters may have additional, perhaps trophic, functions in glial and neuronal differentiation has been under consideration for some time and for which there is substantial precedent in the literature (for review, see Lauder, 1993).

Gallo et al. (1996) have presented evidence that glutamate receptors might be involved in oligodendrocyte progenitor cell proliferation. In this study, we found that quinpirole (a D2/D3 dopamine agonist) caused an increase of $\sim 50 \%$ in the numbers of oligodendrocyte precursors present in 14 DIV cultures. Furthermore, treatment with quinpirole significantly reduced the numbers of oligodendrocytes elaborating membranous sheets, generally taken to represent oligodendrocytes at their most differentiated state. These results suggest that dopamine or some other endogenous D3r ligand, acting through this receptor, could prevent the oligodendrocyte from myelinating prematurely by delaying subsequent myelin sheath elaboration. The effect of the agonist seems to be irreversible, because relatively brief exposure to the drug is sufficient to decrease sheet-bearing cells in vitro. The extent to which dopamine or some other D3r ligand might influence myelination in vivo remains to be determined.

Expression of the D3r in cells in the oligodendrocyte lineage was noted only in the corpus callosum during a developmental stage at which oligodendrocytes are beginning to elaborate processes and ensheathing axons. As brain maturation occurred, the expression of D3r in these cells was found to decrease. In the adult nervous system, only scattered cells were labeled in the corpus callosum, which correlates well with the observed absence of D3r expression in fully mature oligodendrocytes in vitro.

Although innervation by the dopamine system is somewhat restricted, anatomically there are three well defined dopamine systems in the adult brain. The most studied has been the nigrostriatal system. Dopaminergic cell bodies, located in the zona compacta of the substantia nigra, project primarily to the neostriatum and the amygdala. In the second system cell bodies of the mesolimbic dopamine system are located in the ventral tegmental area and innervate the nucleous accumbens and the olfactory tubercles. In the third system, cell bodies primarily from the hypothalamus innervate the external layer of the median eminence. Thus, areas of the brain such as the corpus callosum, in which D3r expression in oligodendrocytes was demonstrated, are surrounded by areas rich in dopamine. Certainly, at the time when oligodendrocyte precursors are dividing and migrating within the brain, i.e., shortly after birth in the mouse, the extracellular concentration of dopamine (which has diffused out of, or is released from the nerve terminal) is relatively high compared with adult levels (Howard et al., 1997), although the reuptake mechanism for the catecholamines is not yet fully developed (Nomura et al., 1976). The high water content of the brain could result in widespread diffusion of dopamine, such that dopamine could act on cells such as oligodendrocyte precursors. As oligodendrocytes reach their fully differentiated state in culture, D3r expression appears to disappear, which would make the fully mature oligodendrocytes refractory to the actions of dopamine or some other D3r ligand, at least through this receptor.

There is accumulating evidence that some neurotransmitters may participate in the modeling of neuronal shape and the outgrowth of their neurites (for review, see Mattson, 1988). Todd (1992) has shown that activation of D2r with quinpirole induced an increase in the neurite length of primary cultures of cortical neurons. More recently, Swarzenski et al. (1994) demonstrated that not only D2r, but also D3r and D4r, may regulate the outgrowth of neuronal processes. Indeed, the modulation of a number of neurotransmitter receptors during early brain development can dramatically influence the cytoarchitecture of different populations of neurons (Chubakov et al., 1986; Hauser et al., 1987; Mattson et al., 1989; Blanton et al., 1990; Lo Turco et al., 1991). It is not unreasonable, then, that in a cell whose primary function is to elaborate myelin membrane, at least the dopamine system, might modulate the cytoarchitecture of the oligodendrocyte in terms of the amounts and timing of myelin formation.

Recently, we reported the presence of the D2r in a subset of mature interfascicular oligodendrocytes in the rat corpus callosum (Howard et al., 1998). This and the present study have shown that cells in the oligodendrocyte lineage are capable of expressing members of the D2 subfamily of receptors. Although this remains to be investigated further, we suggest that the D3 and D2 receptors are expressed at different stages in oligodendrocyte development and that this expression may be involved in regulating myelin formation in the lineage. We propose that the immature oligodendrocytes express D3r, and this may serve to regulate myelin formation by some, as yet unknown, mechanism. This expression normally disappears in mature myelinating oligodendrocytes, rendering the cells unable to respond to dopamine or a related endogenous ligand and therefore enabling the cells to complete their differentiation. In our previous study D2r was not detected in oligodendroglial cells at early stages of brain development associated with oligodendroglial progenitor appearance and proliferation. This suggests that the expression of D3r in cells of the oligodendrocyte lineage occurs after D3r expression.

In summary, we have presented evidence that the D3r is present in cells within the oligodendrocyte lineage and that it may play a role in either the differentiation of oligodendrocytes and/or subsequent membrane formation by these cells. This adds another important function for dopamine in the developing brain beyond its well known role as a neurotransmitter.

\section{REFERENCES}

Ariano MA, Sibley DR (1994) Dopamine receptor distribution in the rat CNS: elucidation using anti-peptide antisera directed against D1A and D3 subtypes. Brain Res 649:95-110.

Barres BA, Schmid R, Sendtner M, Raff MC (1993) Multiple extracellular signals are required for long-term oligodendrocyte survival. Development 118:283-295. 
Blanton MG, Lo Turco JJ, Kriegstein AR (1990) Endogenous neurotransmitter activates $N$-methyl-D-aspartate receptors on differentiating neurons in embryonic cortex. Proc Natl Acad Sci USA 87:8027-8030.

Bongarzone ER, Foster LM, Byravan S, Verity AN, Landry CF, Schonmann V, Amur-Umarjee S, Campagnoni AT (1996) Conditionally immortalized neural cell lines: potential models for the study of neural cell function. In: Methods, a companion to methods in enzymology (Murphy S, ed), pp 489-500. San Diego: Academic.

Bunzow JR, Van Tol HH, Grandy DK, Albert P, Salon J, Christie M, Machida CA, Neve KA, Civelli O (1988) Cloning and expression of a rat D2 dopamine receptor cDNA. Nature 336:783-787.

Cameron RS, Rakik P (1991) Glial cell lineage in the cerebral cortex: a review and synthesis. Glia 4:124-137.

Chubakov AR, Gromova EA, Konovalov GV, Sarkisova EF, Chumasov EI (1986) The effects of serotonin on the morphofunctional development of rat cerebral neocortex in tissue culture. Brain Res 369:285-297.

Demotes-Mainard J, Henry C, Jeantet Y, Arsaut J, Arnauld E (1996) Postnatal ontogeny of dopamine D3 receptors in the mouse brain: autoradiographic evidence for a transient cortical expression. Brain Res Dev Brain Res 94:166-174.

Diaz J, Levesque D, Lammers CH, Griffon N, Martres MP, Schwartz JC, Sokoloff P (1995) Phenotypical characterization of neurons expressing the dopamine D3 receptor in the rat brain. Neuroscience 65:731-745.

Fishburn CS, Belleli D, David C, Carmon S, Fuchs S (1993) A novel short isoform of the D3 dopamine receptor generated by alternative splicing in the third cytoplasmic loop. J Biol Chem 268:5872-5878.

Fishburn CS, Bedford M, Lonai P, Fuchs S (1996) Early expression of D3 dopamine receptors in murine embryonic development. FEBS Lett 381:257-261.

Gallo V, Suergiu R, Giovannini C, Levi G (1989) Expression of excitatory amino acid receptors by cerebellar cells of the type- 2 astrocyte cell lineage. J Neurochem 52:1-9.

Gallo V, Zhou JM, McBain J, Wright P, Knutson PL, Armstrong RC (1996) Oligodendrocyte progenitor cell proliferation and lineage progression are regulated by glutamate receptor-mediated $\mathrm{K}^{+}$channel block. J Neurosci 16:2659-2670.

Gard AL, Pfeiffer SE (1990) Two proliferative stages of the oligodendrocyte lineage (A2B5+O4- and $\mathrm{O} 4+\mathrm{GalC}-$ ) under different mitogenic control. Neuron 5:615-625.

Gehlert DR, Gackenheimer SL, Seeman P, Schaus J (1992) Autoradiographic localization of $\left[{ }^{3} \mathrm{H}\right]$ quinpirole binding to dopamine D2 and D3 receptors in rat brain. Eur J Pharmacol 211:189-194.

Hauser KF, McLaughlin PJ, Zagon IS (1987) Endogenous opioids regulate dendritic growth and spine formation in developing rat brain. Brain Res 416:157-161.

Howard S, Fisher R, Landry C (1997) Alterations in the spontaneous release of dopamine and the density of the DA D2 receptor mRNA after chronic postnatal exposure to cocaine. Brain Res Bull 43:101-106.

Howard S, Landry C, Fisher R, Bezouglaia O, Handley V, Campagnoni AT (1998) The postnatal localization and morphogenesis of cells expressing the dopaminergic D2 receptor gene in rat brain: expression in non-neuronal cells. J Comp Neurol 391:87-98.

Kettenmann H (1989) GABA triggers a Cl- efflux from cultured glial cells. Acta Physiol Scand Suppl 582:50.

Laemmli UK (1970) Cleavage of structural proteins during the assembly of the head of the bacteriophage T4. Nature 227:680-685.

Landwehrmeyer B, Mengod G, Palacios JM (1993a) Differential visualization of dopamine D2 and D3 receptor sites in rat brain. A comparative study using in situ hybridization histochemistry and ligand binding autoradiography. Eur J Neurosci 5:145-153.

Landwehrmeyer B, Mengod G, Palacios JM (1993b) Dopamine D3 re- ceptor mRNA and binding sites in human brain. Brain Res Mol Brain Res 18:187-192.

Larson ER, Ariano MA (1995) D3 and D2 dopamine receptors: visualization of cellular expression patterns in motor and limbic structures. Synapse 20:325-337.

Lauder JM (1993) Neurotransmitters as growth regulatory signals: role of receptors and second messengers. Trends Neurosci 16:233-240.

Levesque D, Diaz J, Pilon C, Martres MP, Giros B, Souil E, Schott D, Morgat JL, Schwartz JC, Sokoloff P (1992) Identification, characterization, and localization of the dopamine $\mathrm{D} 3$ receptor in rat brain using 7-[ $\left.{ }^{3} \mathrm{H}\right]$ hydroxy- $N, N$-di- $n$-propyl-2-aminotetralin. Proc Natl Acad Sci USA 89:8155-8159.

Lo Turco JJ, Blanton MG, Kriegstein AR (1991) Initial expression and endogenous activation of NMDA channels in early neocortical development. J Neurosci 11:792-799.

Mattson MP (1988) Neurotransmitters in the regulation of neuronal cytoarchitecture. Brain Res Rev 13:179-212.

Mattson MP, Lee RE, Adams ME, Guthrie PB, Kater SB (1989) Interactions between entorhinal axons and target hippocampal neurons: a role for glutamate in the development of hippocampal circuitry. Neuron 1:865-876.

Montmayeur JP, Bausero P, Amlaiky N, Maroteaux L, Hen R, Borrelli E (1991) Differential expression of the mouse dopamine receptor isoforms. FEBS Lett 278:239-243.

Nomura Y, Naitoh F, Segawa T (1976) Regional changes in monoamine content and uptake of the rat brain during postnatal development. Brain Res 101:305-315.

Peters A, Palay S, Webster H (1991) The fine structure of the nervous system. Oxford: Oxford UP.

Richtland NM, Kelsoe JR, Segal DS, Kuczenski R (1995) Regional quantification of D1, D2, and D3 dopamine receptor mRNA in rat brain using a ribonuclease protection assay. Mol Brain Res 33:97-103.

Sambrook J, Frisch EF, Maniatis T (1989) Molecular cloning: a laboratory manual. Cold Spring Harbor, NY: Cold Spring Harbor Laboratory.

Sibley DR, Monsma Jr FJ, Shen Y (1992) Molecular neurobiology of dopaminergic receptors. Int Rev Neurobiol 35:391-415.

Sokoloff P, Giros B, Martres MP, Bouthenet ML, Schwartz JC (1990) Molecular cloning and characterization of a novel dopamine receptor (D3) as a target for neuroleptics. Nature 347:146-151.

Sokoloff P, Giros B, Martres MP, Andrieux M, Besancon R, Pilon C, Bouthenet ML, Souil E, Schwartz JC (1992) Localization and function of the D3 dopamine receptor. Arzneimittelforschung 42:224-230.

Swarzenski BC, Tang L, Oh YJ, O’Malley KL, Todd RD (1994) Morphogenic potentials of D2, D3, and D4 dopamine receptors revealed in transfected neuronal cell lines. Proc Natl Acad Sci USA 91:649-653.

Temple S, Raff M (1985) Differentiation of a bipotential glial progenitor cell in a single cell microculture. Nature 313:223-225.

Todd RD (1992) Neural development is regulated by classical neurotransmitters: dopamine D2 receptor stimulation enhances neurite outgrowth. Biol Psychiatry 31:794-807.

Towbin H, Staehlin T, Gordon J (1979) Electrophoretic transfer of proteins from polyacrylamide gels to nitrocellulose sheets: procedure and some applications. Proc Natl Acad Sci USA 76:4350-4354.

Van Tol HHM, Bunzow JR, Guan HC, Sunahara RK, Seeman P, Niznik HB, Civelli O (1991) Cloning of the gene for a human dopamine D4 receptor with high affinity for the antipsychotic clazapine. Nature 350:610-615.

Von Blankenfeld G, Trotter J, Kettenmann H (1991) Expression and developmental regulation of $\mathrm{GABA}_{\mathrm{A}}$ receptor in cultured murine cells of the oligodendrocyte lineage. Eur J Neurosci 3:310-316. 